\title{
The structure of the yield of winter wheat when using herbicides against weeds
}

\author{
S.X.Sullieva ${ }^{1}$, Q.G'.Zokirov ${ }^{2}$ \\ ${ }^{1}$ Termez State University, Associate Professor of "Botany", Ph.D. \\ ${ }^{2}$ Master of Tashkent State Agrarian University
}

\begin{abstract}
This article argues that when weeds in winter wheat fields are grown without eradication, the weeds will have a significant amount of shade, absorb some water and nutrients, and adversely affect the structure of the crop. Puma super $(1 \mathrm{l} /$ to $)$ against cereals, Granstar $(15 \mathrm{~g} /$ to $)$ against biphasic weeds, and the elimination of Kroshka variety of winter wheat resulted in a long spike, a large number of grains in the spikes, spikes and spikes in a single spike. increased grain yield this condition has been reported to improve radically the efficiency of the grain structure when mixed and sprayed with Puma super $(1 \mathrm{l} /$ to $)$, two-stage weed Granstar $(15 \mathrm{~g} /$ to $)$ herbicides against more grain weeds.
\end{abstract} Key words: winter wheat, weeds, monocotyledonous plant, herbicide, wheatgrass, yield.

\section{INTRODUCTION}

Wheat yield depends on the structure of the crop and varies depending on the changes in all agro-technological processes during growth and development.

The results of our experiments show that when weeds in the field of winter wheat are grown without eradication (control option), weeding has a significant negative impact on the structure of the crop, shading, absorption of some water and nutrients.

The effectiveness of the application of herbicides against cereals and dicotyledonous weeds was summarized by the results of experiments conducted over the years of experiments and three years, and it was found that the same cases were observed on the indicators analyzed on average. That is, the combined use of Puma super ( $11 /$ to) and Granstar (15 g/ to) herbicides (especially in early April) compared with the herbicide-free control option resulted in a radical improvement in grain structure and grain yield. found to increase productivity.

It has been observed that under the influence of herbicides used in weed control, the length of the spike is also provided to a certain extent. When the Puma super ( $11 /$ to $)$ herbicide was applied on March 20, this herbicide was observed to be $0.1 \mathrm{~cm}$ longer than the unused control variant, while this figure was $0.2 \mathrm{~cm}$ against the background of the Granstar ( $15 \mathrm{~g} / \mathrm{to}$ ) herbicide when both herbicides were used together. while it was found to be $0.5 \mathrm{~cm}$ longer.

When the mentioned herbicides were applied at the prescribed rates on April 10, it was found that the spike length of wheat was even longer.

Similarly, an increase in the number of grains in the stalks of the Kroshka variety of winter wheat, in which the two-stage weeds of cereals were eliminated by herbicides, was also observed. However, it was found that when the herbicides selected in the experiment were applied on April 10, the grains were more numerous than when applied on March 20.

When we analyzed the data on March 20, when we analyzed the data of Puma super (1 1 / to), Granstar (15 g / to) herbicide against cereals and dicotyledonous weeds separately and together, we witness the following cases.

When Puma super ( $11 /$ to) herbicide was applied, the number of spikes in the spikes when the weeds were eradicated on March 20 was 1 compared to the control variant without this herbicide, and 1 when compared to the control variant when the Granstar ( $15 \mathrm{~g} /$ to) herbicide was 
applied. , Was observed to be more than 6, and it was found that the number of spikes per spike increased by 2.6 when both herbicides were used together.

However, the effectiveness when the experimental herbicides were applied separately and together on April 10 was characterized by the fact that the number of ears of winter wheat in the Kroshka variety was higher than when the herbicides were applied on March 20.

The number of grains in the ears of winter wheat was also significantly increased when the Kroshka variety of cereals and dicotyledonous weeds were eliminated by herbicides Puma super (1 1/ to) and Granstar (15 g / to). However, this situation was manifested in an increase in the number of grains in more spikes. That is, when the herbicides were applied on March 20, the number of grains in the control variant was 30.7, 2 against the background of Puma super ( 11 / to) herbicide, 3 against the background of Granstar ( $15 \mathrm{~g} /$ to) herbicide and both herbicides together when applied, the number of grains in the ears was observed to be 5.3 times greater. It was found that the effectiveness of the above-mentioned norms of herbicides was more effective in increasing the number of grains when applied on April 10th.

It was observed that the increase in grain mass from one grain of Kroshka variety of winter wheat was greater when herbicides and dicotyledonous weeds were eliminated in the experimental field by herbicides. Especially if both herbicides are used together, an increase in grain yield from 0.04 grams per grain is one of the key indicators in ensuring an increase in grain yield.

Thus, the use of Puma super ( $11 /$ to $)$ herbicide against cereals and Granstar (15 g / to) herbicide against dicotyledonous weeds is the main tool to improve crop structure and increase grain yield in the conditions of ancient agricultural lands of Surkhandarya region. In particular, the effectiveness of the combined application of these herbicides against cereals and dicotyledonous weeds is further demonstrated in the crop structure.

Scientific sources from the 1980s and 1990s found that herbicides were highly effective when mixed with each other, mineral fertilizers, and other chemicals, and used once. In particular, when herbicides are mixed with each other and applied, herbicide sprayers mounted on tractors are repeatedly used to control weeds in the winter wheat field, which also increases the cost of weeding.

The presence of selective action when herbicides are used to control weeds in winter wheat fields requires the use of several herbicides in the control of weeds belonging to different species.

The results of our experiments (Table 1) show that when Puma super ( $11 /$ to) herbicide Granstar (15 g / to) herbicide was applied separately and together against herbicides, the herbicide yield was significantly higher than in the non-herbicide control variant. found to increase.

Table 1

Dependence of the yield of winter wheat Kroshka variety on the degree of weed control by herbicides

\begin{tabular}{|c|c|c|c|c|c|c|c|}
\hline \multirow[t]{2}{*}{ № } & \multirow{2}{*}{$\begin{array}{l}\text { Experiment } \\
\text { option } \\
\text { lari }\end{array}$} & \multicolumn{4}{|c|}{ Productivity, ts / to } & \multicolumn{2}{|c|}{$\begin{array}{lr}\text { Difference } & \text { with } \\
\text { respect to control } \\
(\mathbf{s t}),+,-\end{array}$} \\
\hline & & $2009 y$ & $2010 y$ & 2011 y & middle & ts/to & $\%$ \\
\hline \multicolumn{8}{|c|}{ When the herbicide is applied on March 20th } \\
\hline 1 & I variant $(\mathrm{st})$ & 31,3 & 34,4 & 32,8 & 32,8 & - & 100,0 \\
\hline 2 & II variant & 45,3 & 50,1 & 48,5 & 47,9 & $+15,1$ & 146,0 \\
\hline 3 & III variant & 46,9 & 49,5 & 47,3 & 47,9 & $+15,1$ & 146,0 \\
\hline \multirow[t]{2}{*}{4} & IV variant & 56,7 & 57,3 & 56,1 & 56,7 & $+23,9$ & 172,8 \\
\hline & $\mathrm{Sx}, \%$ & 0,36 & 0,17 & 0,26 & & & \\
\hline
\end{tabular}




\begin{tabular}{|l|l|l|l|l|l|l|l|}
\hline & EKF05 $=$ ts / to & 3,11 & 1,10 & 1,75 & & & \\
\hline \multicolumn{7}{|l|}{ When the herbicide is applied on April 10th } \\
\hline 1 & I variant(st) & 30,1 & 31,5 & 29,8 & 30,4 & - & 100,0 \\
\hline 2 & II variant & 47,3 & 48,1 & 47,1 & 47,4 & $+17,0$ & 155,9 \\
\hline 3 & III variant & 47,8 & 49,7 & 48,1 & 48,5 & $+18,1$ & 159,5 \\
\hline 4 & IV variant & 59,5 & 61,2 & 60,5 & 60,4 & $+30,0$ & 198,7 \\
\hline & Sx, \% & 0,28 & 0,24 & 0,16 & & & \\
\hline & EKF05 $=$ ts / to & 1,86 & 1,52 & 1,04 & & & \\
\hline
\end{tabular}

However, it has been observed that grain yield varies depending on the duration, type and method of application of herbicides.

First of all, the following cases were observed when analyzing the grain yield of the control option without herbicides on the duration of herbicide application. It was observed that the grain yield of the control variant varied in the years of the experiment, in places where herbicides were used and not used, due to the fact that in the experimental fields the herbicides were in different places in terms of application times. However, it can be assumed that the difference in grain foreign in the control options does not exceed 2.0-2.5 ts / to due to the error between the experimental options. Because the smallest difference between the experimental options (EKF) is 1.10-3.11, this figure is a natural difference between the experimental options and the repetitions, and it is recognized that experiments are conducted correctly on such differences that occur in field experiments.

According to the first experiment on eradication of cereals and dicotyledonous weeds in winter wheat fields by application of herbicides on March 20, the grain yield in the control variant without herbicides was 31.3-34.4 t / to, while Puma super (1 $1 /$ e) The grain yield after herbicide control was 45.3-50.1 t / to for the experimental foreign, and the three-year average was 15.1/to compared to the control option without the use of additional grain herbicides. When Granstar (15 g/ to) herbicide was used against biphasic weeds, the grain yield varied sharply from year to year (46.5-49.5 t / to) and averaged $47.9 \mathrm{t} /$ to compared to the control variant. , Showed the formation of an additional grain yield of 1 ts / to. However, when both herbicides were used together at established rates, the additional grain yield increased by $72.8 \%$. That is, the average grain yield on three-year experiments was 56.7 ts / to when herbicides were used together, and the additional grain yield was 23.9 ts / to compared to the control option where no herbicides were used. These cases can be attributed to the negative effects of biphasic weeds when the Puma super ( $11 /$ to) herbicide was applied separately and the grain yield was 8.8 ts / to lower than when the Granstar (15 g/ to) herbicide was used together.

Even when the Granstar (15 g / to) herbicide is used alone, it is natural that the lower grain yield than when both herbicides are used together is due to the adverse effects of cereal weeds. This is because cereals and dicotyledonous weeds grow simultaneously in winter wheat fields, which has a negative impact on productivity. When Puma super (1 $1 /$ to $)$ and Granstar (15 g / to) herbicides are used together, the grain yield increases dramatically by eliminating both cereal and dicotyledonous weeds at the same time and creating full conditions for free growth and development of winter wheat.

According to the second experiment, the additional grain yield of Puma super ( $11 /$ to $)$ herbicide against grain, Granstar (15 g / to) herbicide against dicotyledonous weeds on April 10 increased to 6.1 ts / to compared to that applied on March 20. This situation can be explained by the 
fact that the herbicides were applied on March 20, and despite the elimination of weeds, new ones sprouted and reduced yields due to the negative impact on the growth and development of winter wheat. This is because on April 10, all types of weeds that have been treated with herbicides will be fully germinated and eradicated by herbicides (corn and biphasic). For this reason, it was found that when the Puma super (1 1/ to) was applied on March 20, the additional grain yield was 15.1 ts / to, while when applied on April 10, this figure increased to 2.0 ts / to. It was also observed that the herbicide Granstar (15 g / to) was applied on April 10, an increase of 3.0 ts / ha compared to that applied on March 20. When the herbicides are applied together on April 10, when the weeds are fully germinated, the additional grain yield averages up to 30 ts / ha, increasing the total average grain yield to 60.4 ts / to.

This means that when corn and dicotyledonous weeds are common in winter wheat fields, Puma super (1 l / to) and Granstar (15 g / to) herbicides are mixed against them and applied once to increase grain yield by weeding wheat fields from such weeds. up to two contributions can be achieved.

We selected fields where winter wheat was grown a year before the experiment and planned to grow winter wheat the following year, and identified fields with high yields of cereals and dicotyledons. Even before the experiments, we calculated such weeds and then applied herbicides according to the experimental scheme. Therefore, it was observed that there were significant differences in yield between herbicides not used and experimental options used. Usually herbicides are also applied to crops with a lot of weeds.

\section{LIST OF USED LITERATURE:}

1. Vasilchenko I. T, Pidotti O. A. Keys to weeds of irrigated agriculture. M "Kolos", 1970-367 p.

2. Xamroev A. Sh. and others. Protection of grain and rice from pests, diseases and weeds. State Chemical Commission under the Cabinet of Ministers of the Republic of Uzbekistan. Tashkent, 1999 -71-85 p.

3. Vitsenko V.P., Kolyushnikov V.T. Application under corn and herbicides. F: "Chemicalization of the agricultural economy". No. 2, 1990- 71-72 p.

4. Vorobiev G. Ya. Use the entire arsenal of weed control products. F: "Agriculture". No. 4, 1986-11-12 p.

5. 5 Sedelnikov M.P. Stop thoughtless chemicalization of agriculture. F: "Agriculture" No. 10, 1990-21-23 p.

6. Taskaeva A.G., Taskaev V.P. Determination of the weed severity coefficient. F: "Agriculture" No. 8, 1990-73-75 p.

7. Andreev A.S., Tereshchuk V.S. Fenagon on barley crops. F: "Chemistry in Agriculture" No. 6, 1986- 55-57 p.

8. Babich A.A, Harrow V.P. Weed control, taking into account the competitiveness of crops. F: "Agriculture", No. 2, 1986- 41-42 p.

9. Bazdyrov G. Weeds are the enemy of the harvest. F: "Agriculture" .№2.1985 -7-9s. 